\title{
ad and ay subtypes of hepatitis B antigen in a case of hypogammaglobulinaemia
}

\author{
J. W. M. LAWTON 1 , R. HOPKINS, I. C. PATERSON, AND P. C. DAS
}

From the South-East Regional Blood Transfusion Service, Royal Infirmary, Edinburgh, and Respiratory Unit, Northern General Hospital, Edinburgh

SYNOPSIS We describe the finding of $d$ and y specificities of hepatitis $B$ surface antigen $\left(\mathrm{HB}_{\mathrm{s}} \mathrm{Ag}\right)$ in a case of hypogammaglobulinaemia of the 'common variable' type treated with fresh frozen plasma infusions. Absorption studies show that the two specificities are on separate particles, suggesting dual infection. It raises important questions regarding the relationship between $\mathrm{HB}_{\mathrm{s}} \mathrm{Ag}$ persistence and the immune status of the carrier.

Levine and Blumberg (1969) first suggested that $\mathrm{HB}_{\mathrm{s}} \mathrm{Ag}$ could be separated into subtypes with a shared group specificity designated a. The principal subtype specificities have since been defined and designated $d$ and $y$ (le Bouvier, 1971) and $w$ and $r$ (Bancroft et al, 1972). These pairs of specificities seem to represent two allelomorphic systems, the four phenotypes being adw (D), adr, ayw (Y), and ayr. The last is exceedingly rare in a European population. Increasingly, hepatitis reference laboratories are able to test for $\mathrm{d}$ and $\mathrm{y}$ specificities using monospecific antisera. As a rule, the two common phenotypes, $\mathrm{D}$ and $\mathrm{Y}$, are mutually exclusive. The finding of $d$ and $y$ specificities in the same serum is rare. It is even less common to find both $\mathrm{d}$ and $\mathrm{y}$ on separate particles, and the few reported cases were all on long-term haemodialysis (van Kooten-Kok Doorschodt et al, 1972; Soulier and Couroucé-Pauty, 1973). In our present report immunoabsorption studies indicate that the two specificities reside on separate particles, suggesting dual infection.

To the best of our knowledge there are no previous reports of this finding in hypogammaglobulinaemia. Such patients, if treated with fresh frozen plasma infusions, may be at particular risk of becoming hepatitis B virus (HBV) carriers.

\section{Case Report}

A 57-year-old Caucasian man had had recurrent respiratory infections since adolescence. In 1957, aged 39 years, he was investigated for recurrent cough and purulent sputum. The bronchogram was

Received for publication 20 May 1975

${ }^{1}$ Present address : Immunology Unit, Dept. of Pathology, Queen Mary Hospital, Hong Kong normal and a diagnosis of chronic suppurative bronchitis was made. In 1962 he was admitted to hospital with bilateral bronchopneumonia and found to have a serum $\gamma$-globulin level of $0.2 \mathrm{~g} / 1$. Regular therapy with pooled normal human $\gamma$-globulin was begun and he was much improved subsequently. After four years he began to have anaphylactic reactions to the $\gamma$-globulin and treatment was discontinued. Despite continuous prophylactic antibiotic therapy he deteriorated and in 1969, after an attempt at desensitization, $\gamma$-globulin therapy was resumed. Further anaphylactic reactions ensued and in September 1971 he was started on infusions of fresh frozen plasma, initially one per week and later on every second week, along with continuous oral ampicillin. In March 1972 he suffered an episode of general malaise, anorexia, and upper abdominal pain. He was not jaundiced and his serum bilirubin, SGOT, SGPT, and LDH levels were normal, but the serum alkaline phosphatase was raised at 263 IU/1. A liver biopsy was not done and serum was not tested for $\mathbf{H B}_{\mathbf{s}} \mathrm{Ag}$. Subsequently the alkaline phosphatase returned to normal. In September 1973, plasma infusions were reduced to three-weekly intervals and on this regimen he has since remained reasonably well.

In June 1974 his immune status was fully investigated, with the following results:

Peripheral blood:

Absolute lymphocyte and granulocyte counts were normal.

Serum immunoglobulins:

IgG $30 \mathrm{IU} / \mathrm{ml}, \operatorname{IgA} 23 \mathrm{IU} / \mathrm{ml}$, IgM $28 \mathrm{IU} / \mathrm{ml}\left(2 \frac{1}{2}\right.$

weeks after plasma infusion).

Serum complement:

C3 and C4 levels normal. 
Red cell serology:

Direct and indirect antiglobulin tests and screen for anti-erythrocyte antibodies negative

Iso-agglutinin titres:

Iso-agglutinins not detectable (red cells, group $\mathbf{O}$ )

Phagocyte function:

Phagocytosis and intracellular killing of Staphylococcus aureus by blood leucocytes, stimulated NBT test, and leucocyte chemotaxis (migration through $3 \mu$ Millipore filter), all normal

Lymphocyte function:

Stimulation of blood lymphocytes (incorporation of 3H-thymidine into DNA) by mitogens (phytohaemagglutinin, conconavolin $\mathrm{A}$, and poke-weed mitogen) and by pooled allogeneic cells, all normal

Blood lymphocyte subpopulations:

The $\mathrm{T}$ cell count ( $\mathrm{E}$ rosettes) was normal; B cells (EAC rosettes) $6 \%$ (normal 10-20\%)

Skin testing:

Positive delayed hypersensitivity response to mumps antigen; no response to PPD and Candida

Antibody response to tetanus toxoid:

No antibody detected (passive haemagglutination technique) before and 14 days after immunization

These results confirmed hypogammaglobulinaemia and demonstrated intact cell-mediated immunity, both phagocytic and lymphoid.

In September 1974 routine testing in a diagnostic laboratory (Regional Virus Laboratory, City Hospital, Edinburgh) showed that the patient's serum was positive for $\mathrm{HB}_{\mathrm{S}} \mathrm{Ag}$ (by counter-immunoelectrophoresis, CIEP). At this time the liver was not enlarged and liver function tests (serum bilirubin, GOT, GPT, and alkaline phosphatase) were normal.

\section{HBaA TESTING AND SUBTYPING}

Methods used in our laboratory to confirm $\mathrm{HB}_{\mathrm{s}} \mathrm{Ag}$ positivity were haemagglutination inhibition (HAI), as previously described by Hopkins and Das (1973), haemagglutination (turkey cell HA kit, Wellcome Reagents Ltd), and radioimmunoassay (Austria I RIA kit, Abbot Labs, Ltd). To identify and titre $\mathrm{d}$ and $\mathrm{y}$ specificities, monospecific antisera were used in the HAI assay as previously described (Hopkins and Das, 1974).

\section{IMMUNOABSORPTION}

In order to determine whether $\mathrm{d}$ and $\mathrm{y}$ were associated with the same or separate particles, $0.5 \mathrm{ml}$ of a 1 in 5 serum dilution was incubated with an equal volume of monospecific anti-y serum ${ }^{1}$ at $37^{\circ} \mathrm{C}$ for 1 hour, and at $4^{\circ} \mathrm{C}$ for 16 hours. The mixture was

${ }^{1}$ Prepared by affinity chromatography. Antiserum containing anti-ayw activity was processed on an activated Sepharose $4 B$ column to which was coupled $\mathrm{HB}_{\mathrm{S}} \mathrm{Ag}$ of specificity adw, removing anti-aw activity. then centrifuged at $30000 \times \mathrm{g}$ for 60 minutes to pellet immune complexes. The supernatant and pellet were tested for $a, d$, and $y$ antigeneic specificities by HAI and the supernatant for the presence of anti-y antibody by direct haemagglutination.

\section{ELECTRON MICROSCOPY}

Serum was centrifuged at $120000 \times \mathrm{g}$ for 4 hours and the pellet washed once in saline and reconstituted to $1 / 20$ th of the original volume. One drop of this suspension was mixed with an equal volume of $2 \%$ phosphotungstic acid (pH 6.8) and absorbed onto a collodion-coated copper grid (400 mesh) for examination in the electron microscope (Hitachi 12A).

\section{Results}

HBSAg SUBTYPES

$\mathrm{HB}_{\mathbf{S}} \mathrm{Ag}$ positivity was confirmed in our laboratory by HAI, HA, and RIA. Both d and y subspecificities were detectable in the serum to titres of 1 in 200 and 1 in 100 respectively (HAI method).

The results of immunoabsorption against monospecific anti-y are summarized in the table. Anti y was present in the supernatant, showing that antibody was present in excess. Therefore apparen absence of y specificity in the pellet was presumable because all $\mathrm{y}$ determinant combining sites were occupied by anti-y. No y antigen was detectable in the supernatant while $\mathrm{d}$ subspecificity remained at the original titre $(1: 20$, equivalent to $1: 200$ of the undiluted serum), indicating that $d$ bearing particles had not complexed with anti-y, that is, $d$ and $y$ subspecificities were on separate particles. The reciprocal absorption (using monospecific anti-d) was performed on a serum sample taken at a different time; d subspecificity was removed, leaving y undiminished in the supernatant at a titre of 1:1000. Because specificity a is common to all subtypes, the

\begin{tabular}{llll}
\hline & Titres & \\
\cline { 2 - 4 } $\begin{array}{l}\text { Antigen } \\
\text { Specificity }\end{array}$ & $\begin{array}{l}\text { Serum }{ }^{2}(1: 10 \\
\text { Dilution) before } \\
\text { Absorption }\end{array}$ & $\begin{array}{l}\text { Supernatant } \\
\text { after Absorption }\end{array}$ & Pellet \\
\hline a & $1 / 1600$ & $1 / 1000$ & $1 / 200$ \\
d & $1 / 20$ & $1 / 20$ & Negative \\
y & $1 / 10$ & Negative & Negative \\
\hline
\end{tabular}

Table Immunoabsorption with monospecific anti-y

${ }^{1}$ Monospecific anti-y antiserum prepared by affinity chromatography 'Titres performed on whole serum: figures corrected for 1:10 dilution incurred during absorption

Reciprocal absorption of a separate serum sample using monospecific anti-d antiserum removed $d$ antigen leaving $y$ antigen undiminished (see text). 


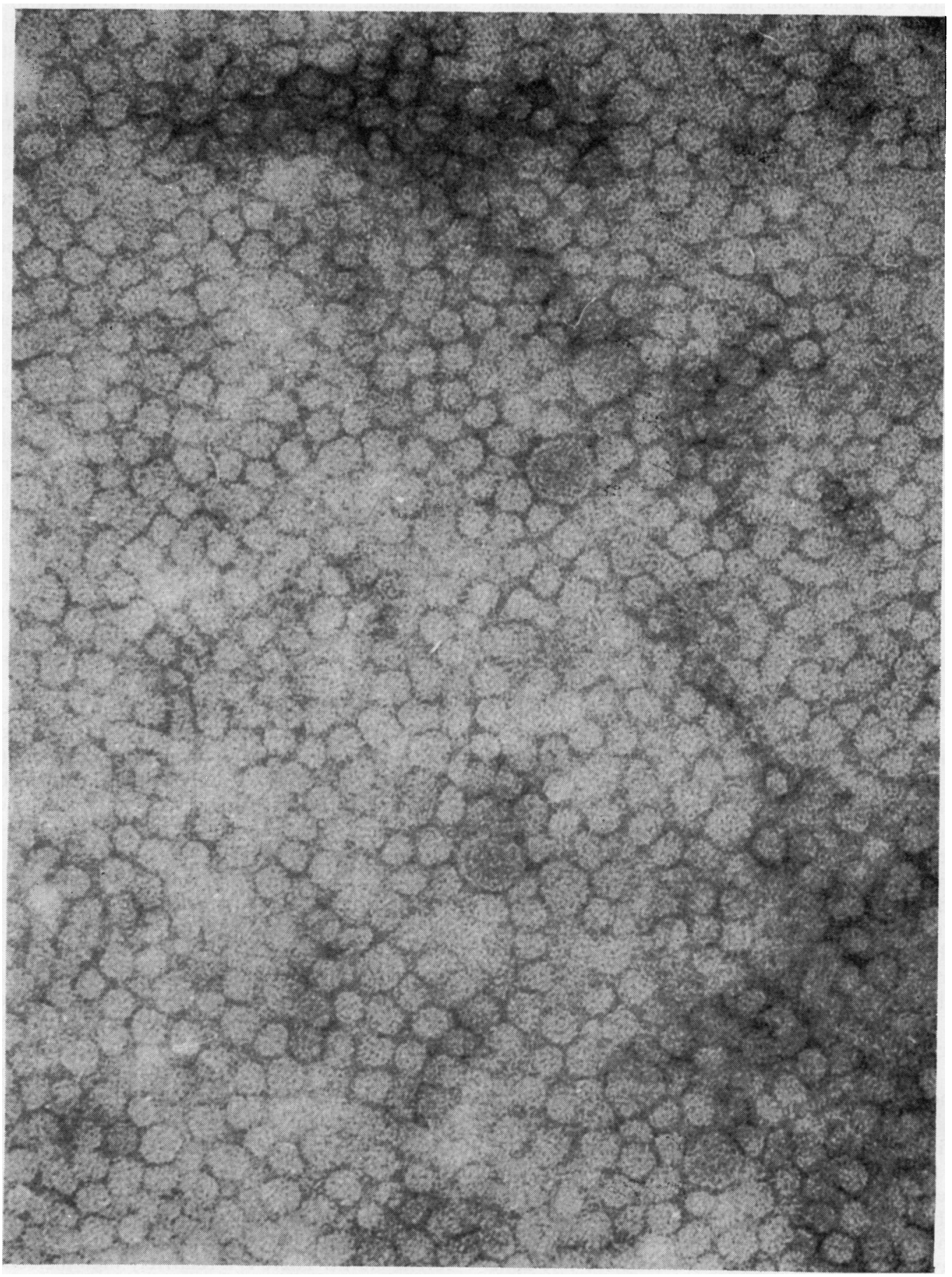
Figure Electron micrograph $(\times 210000)$ showing $20 \mathrm{~nm}$ spherical and rod-like structures of $\mathrm{HB} \mathrm{B}_{8} \mathrm{Ag}$ and $42 \mathrm{~nm}$
Dane particles 
presence of a in both the pellet and supernatant provided good supporting evidence that we were dealing with two distinct populations of $\mathrm{HB}_{\mathbf{s}} \mathrm{Ag}$ particles.

\section{ELECTRON MICROSCOPY}

EM studies (figure) showed the characteristic spherical and rod-like structures, $20 \mathrm{~nm}$ in diameter, as well as numerous $42 \mathrm{~nm}$ Dane particles, believed to represent the complete infectious virion.

\section{Review of Patient's Sera and Plasma Donors}

Retrospective investigation of a serum sample of 7 February 1973 showed the presence of both $\mathrm{HB}_{\mathrm{s}} \mathrm{Ag}$ specificities (at the same titres as in 1974), but a sample of 2 December 1970 was negative. We were unable to locate any serum samples taken between these dates. From the beginning of plasma infusions on 7 September 1971 until 7 February 1973 he had received 72 donations of plasma. Screening of all blood donations for $\mathrm{HB}_{\mathrm{s}} \mathrm{Ag}$ by the CIEP method was begun in September 1971. Initially the patient received four donations of plasma that had not been tested. The remaining 68 donations were $\mathrm{HB}_{\mathbf{s}} \mathrm{Ag}$ negative by the relatively insensitive CIEP test. None of the 72 donors involved has subsequently been found to be positive by CIEP or by the more sensitive HAI technique which has been in routine use since the beginning of 1974 .

\section{Review of Other Hypogammaglobulinaemic Patients}

Recognizing the possibility that other similar patients may have become $\mathrm{HB}_{\mathrm{s}} \mathrm{Ag}$ carriers, we tested all the hypogammaglobulinaemic patients known to us in the Edinburgh area. There were nine such patients in all; seven had received $\gamma$-globulin therapy at some stage, and one had been receiving fresh frozen plasma infusions for two and a half years. All were negative for $\mathrm{HB}_{\mathrm{s}} \mathrm{Ag}$ by the $\mathrm{HAI}$ method.

\section{Discussion}

Generally speaking the $d$ and $y$ specificities of $\mathrm{HB}_{\mathrm{s}} \mathrm{Ag}$ are mutually exclusive, and it is exceptional to find both specificities in the same serum. There are three reports where $d$ and $y$ specificities may have been present on separate particles in patients on haemodialysis. Ling et al (1973) reported two such cases indicated by the results of radioimmunoassay, but cross absorption studies were not done. Van Kooten Kok-Doorschodt et al (1972) described a case and Soulier and Couroucé-Pauty (1973) reported two further cases where $d$ and $y$ sub- specificities could be separated by absorption. The absorption studies which we describe clearly indicate $\overrightarrow{\overrightarrow{\vec{\sigma}}}$ that the $a \mathrm{~d}$ and $a \mathrm{y}$ subtypes were present as distinct $\frac{\text { - }}{-}$ populations. The simplest and most likely ex- $\overrightarrow{\vec{O}}$ planation is that the patient underwent dual infection from two positive donors. Unfortunately, serum samples were not available to show whether the two subtypes appeared sequentially. Therefore there is the small possibility that he was infected by one donor who carried both subtypes.

It is now widely believed that the immune response $\overrightarrow{0}$ to HBV determines the nature and degree of tissue $\vec{\overrightarrow{ }}$ damage and whether the subject develops the carrier $\vec{\omega}$ state. The HBV per se is probably not cytocidal to $\frac{5}{2}$ hepatocytes (Hand and Finlayson, 1973) but cell damage results primarily from a cell-mediated ${ }_{\infty}^{N}$ response of the delayed hypersensitivity type (directed $\overrightarrow{-}$ against the virus or altered cell components). This is supported by several lines of evidence. If cellular $\stackrel{\mathrm{W}}{\mathrm{S}}$ immune responses are heightened by giving transfer 은 factor in chronic active hepatitis ( $\mathbf{H B}_{\mathbf{s}} \mathbf{A g}$ positive), then there is a transient rise in serum transaminase $Z$ levels (Shulman et al, 1974). It has been repeatedly shown, using leucocyte-migration inhibition and $\frac{\Phi}{3}$ lymphocyte transformation tests, that clinical $\underset{\mathbb{\Phi}}{\mathbb{D}}$ disease is associated with a positive in vitro response to $\mathrm{HB}_{\mathrm{s}} \mathrm{Ag}$, while in the chronic carrier there is $g \overrightarrow{0}$ negative response (Dudley et al, 1972; Laiwah et $\frac{9}{9}$, or 1973).

Specific antibody alone is protective if prese before infection (Sutnick et al, 1972) or when given $\frac{\partial}{0}$ prophylactically after accidental inoculation (Das and Hopkins, 1974). Antibody may also mediate $\underset{\mathscr{Q}}{\mathbb{Q}}$ cellular cytotoxicity to liver cells in chronic active $\overrightarrow{\vec{F}}$ hepatitis (Eddleston and Williams, 1974). In estab- 응 lished $\mathrm{HBV}$ infection the cell mediated immune response would seem to act in conjunction with circulating antibody to eliminate the virus; that is, cytotoxic $\mathbf{T}$ or $\mathbf{K}$ cells cause lysis of infected hepato-? cytes, and the liberated viral particles are then $\frac{0}{3}$ neutralized by circulating antibody. Thus it can be postulated that both the cellular and humoral arms $ᄋ$ of the immune response must be impaired (or inadequate) to allow the development of the $\mathrm{HB}_{\mathrm{s}} \mathrm{Ag}$ 의 carrier state with little or no liver damage. In the $>$ case we describe here, no deficiency in $\mathrm{T}$ cell function could be detected; however, it is possible that an specific defect existed which was not detectable by ${ }^{\circ}$ the screening tests used, none of which was specific 0 for $\mathrm{HB}_{\mathrm{s}} \mathrm{Ag}$.

There is ample epidemiological evidence indicating that impaired immune function predisposes to the carrier status. There is a relatively high incidence of $\frac{\text { }}{\Phi}$ $\mathrm{HB}_{\mathbf{s}} \mathrm{Ag}$ carriers among institutionalized cases of $\stackrel{?}{+}$ Down's syndrome (Sutnick et al, 1968), chronic 0 renal disease on haemodialysis (Turner and White, $\frac{\vec{P}}{\mathbb{Q}}$ 
1969), transfused lymphocytic leukaemia (Sutnick et al, 1970), and lepromatous leprosy (Blumberg and Melartin, 1970); in all these conditions cellular immune responses or both cellular and humoral responses are impaired. Tolerance induction may be important, and this is a plausible explanation for the high incidence of carriers in infants exposed to the $\mathrm{HB}$ virus in neonatal or prenatal life, reported by Schweitzer et al (1972).

It is well recognized that generally there is no increased susceptibility to viral infections in hypogammaglobulinaemia, where cell mediated immunity and interferon production are intact. However, absence of specific antibody would increase the susceptibility to any virus which gains entry via the blood stream. This seems to be so in the case of inoculated HBV (see above). Moreover, established immunity to one subtype may confer immunity to infection by the other subtype, by virtue of antibody against common specificities, provided that the challenge dose of virus is not overwhelming. From these considerations we conclude that hypogammaglobulinaemic patients are more susceptible to HBV infection and to reinfection by the other subtype.

It is noteworthy that we failed to identify the infective donor(s) despite retrospective checking of every plasma donation against the records of $\mathrm{HB}_{\mathbf{s}} \mathrm{Ag}$ positive donors. The majority of the people who gave the original 72 donations of plasma would have been tested by CIEP or HAI at subsequent donations and none has proved positive. Nevertheless our finding of both $d$ and $y$ subspecificities in this case of hypogammaglobulinaemia indicates the strong possibility of double infection from plasma infusions. Patients with hypogammaglobulinaemia who receive only pooled human $\gamma$-globulin are exposed to a negligible risk, but those who develop severe reactions to $\gamma$-globulin and require plasma infusions may be at particular risk of becoming HBV carriers. We recommend that all hypogammaglobulinaemic patients having regular fresh frozen plasma should be monitored closely for $\mathrm{HB}_{\mathrm{s}} \mathrm{Ag}$.

We wish to thank Dr I. W. B. Grant, consultant physician, Respiratory Unit, Northern General Hospital, Edinburgh for kind permission to publish this case. We also acknowledge the advice and encouragement of Dr J. D. Cash, Director, South East Scotland Regional Blood Transfusion Centre, Edinburgh.

Request for reprint to P.C.D. at B.T.S.

\section{References}

Bancroft, W. H., Mundon, F. K., and Russell, P. K. (1972).
Detection of additional antigeneic determinants of hepatitis B antigen. J. Immunol., 109, 842-848.

Blumberg, B. S., and Melartin, L. (1970). Australia antigen and lepromatous leprosy; studies in South India and elsewhere. Int. J. Leprosy, 38, 60-67.

Das, P. C., and Hopkins, R. (1974). Immunoprophylaxis of hepatitis $B$ by human anti-HB-Ag immunoglobulin following accidental inoculation. (1974). Brit. J. Haemat., (Abstract), 28, 147-148.

Dudley, F. J., Giustino, V., and Sherlock, S. (1972). Cellmediated immunity in patients positive for hepatitisassociated antigen. Brit. med. J., 4, 754-756.

Eddleston, A. L. W. F., and Williams, R. (1974). Inadequate antibody response to $\mathrm{HB}-\mathrm{Ag}$ or suppressor T-cell defect in development of active chronic hepatitis. Lancet, 2, 1543-1545.

Hand, R., and Finlayson, N. D. C. (1973). Persistent viral hepatitis. Amer. J. Med., 55, 799-810.

Hopkins, R., and Das, P. C. (1973). A tanned cell haemagglutination test for the detection of hepatitis-associatedantigen (Au-Ag) and antibody (anti-Au). Brit. J. Haemat., 25, 619-629.

Hopkins, R., and Das, P. C. (1974). Australia antigen (HB-Ag) subtyping by a sensitive tanned cell haemagglutination-inhibition technique. Brit. J. Haemat., 27, 501-506.

Laiwah, A. A. C. Y., Chaudhuri, A. K. R., and Anderson, J. R. (1973). Lymphocyte transformation and leucocyte migration-inhibition by Australian antigen. Clin. exp. Immunol., 15, 27-34.

le Bouvier, G. L. (1971). The heterogeneity of Australia antigen. J. infect. Dis., 123, 671-675.

Levine, C., and Blumberg, B. S. (1969). Additional specificities of Australia antigen and the possible identification of hepatitis carriers. Nature. (Lond.), 221, 195-196.

Ling, C. M., Irace, H., Decker, R., and Overby, L. R. (1973). Hepatitis $B$ virus antigen: validation and immunologic characterization of low-titer serums with ${ }^{125} \mathrm{I}$-antibody. Science, 180, 203-205.

Schweitzer, I. L., Wing, A., McPeak, C., and Spears, R. L. (1972). Hepatitis and hepatitis-associated antigen in 56 mother-infant pairs. J. Amer. med. Ass., 220, 1092-1095.

Shulman, S., Schulkind, M., and Ayoub, E. (1974). Transfer factor therapy of chronic active hepatitis. (Letter). Lancet, 2, 650 .

Soulier, J. P., and Couroucé-Pauty, A. M. (1973). New determinants of hepatitis B antigen (Au or HB antigen). Vox. Sang. (Basel), 25, 212-234.

Sutnick, A. I., London, W. T., Gerstley, B. J. S., Cronlund, M. M., and Blumberg, B. S. (1968). Anicteric hepatitis associated with Australia antigen; occurrence in patients with Down's syndrome. J. Amer. med. Ass., 205, 670-674.

Sutnick, A. I., London, W. T., Blumberg, B. S., Yankee, R. A., Gerstley, B. J. S., and Millman, I. (1970). Australia antigen (a hepatitis-associated antigen) in leukaemia.J.nat. Cancer Inst., 44, 1241-1249.

Sutnick, A. I., London, W. T., Blumberg, B. S., and Vierucci, A. (1972). Australia antigen, posttransfusion hepatitis, and the chronic carrier state. Amer.J. Dis. Child., 123, 392-400.

Turner, G. C., and White, G. B. B. (1969). SH antigen in haemodialysis-associated hepatitis. Lancet, 2, 121-125.

van Kooten Kok-Doorschodt, H. J., van der Akker, R., and Gispen, R. (1972). Determination and distribution of two types of hepatitis-associated antigen. J. infect. Dis., 126, 117-122. 